\title{
Nickel-Phosphorous Development for Total Solar Irradiance Measurement
}

\author{
F. Carlesso ${ }^{1}$, L. A. Berni ${ }^{1}$, L. E. A. Vieira ${ }^{1}$, G. S. Savonov ${ }^{1}$, \\ M. Nishimori ${ }^{1}$, A. Dal Lago ${ }^{1}$ and E. Miranda ${ }^{1}$ \\ ${ }^{1}$ National Institute for Space Research, INPE \\ Av. dos Astronautas 1758, 12227-010 , São José dos Campos, SP, Brazil \\ email: fccarlesso@gmail.com
}

\begin{abstract}
The development of an absolute radiometer instrument is currently a effort at INPE for TSI measurements. In this work, we describe the development of black Ni-P coatings for TSI radiometers absorptive cavities. We present a study of the surface blackening process and the relationships between morphological structure, chemical composition and coating absorption. $\mathrm{Ni}-\mathrm{P}$ deposits with different phosphorous content were obtained by electroless techniques on aluminum substrates with a thin zincate layer. Appropriate phosphorus composition and etching parameters process produce low reflectance black coatings.
\end{abstract}

Keywords. Black Nickel-Phosphorous, Active Cavity Radiometers, Low Reflectance Coating

\section{Introduction}

Variations in total solar irradiance (TSI) influence the Earths climate (Steinhiber et al. 2009). The global energy balance and climate can be impacted by changes in TSI, making accurate solar measurements important to discern the long-term effects of this influence (Haigh 2007). TSI measurements have been made continually by different space-borne instruments since 1978. These measurements rely on active cavity radiometers, which use black interior surfaces to absorb incident sunlight. The conical cavity is constructed mainly of electrodeposited silver due to the high thermal conductivity and use black film interior surfaces to absorb incident sunlight. Cavities have a wire resistor in the outer wall encapsulated with epoxy, which provides heat close to the region heated by solar radiation. On the external wall of the cavity is deposited chromium and copper to be a base and gold to reduce the radiative losses to the environment. Ni-P was first applied in active cavity radiometers for measuring solar irradiance in TIM (Total Irradiance Monitor) instrument aboard SORCE spacecraft and has advantages over traditionally used black paints providing robustness to solar exposure and having good thermal conductivity (Kopp 2014). Ni-P alloy coating has been found important applications in different fields of science and finishing industries due high hardness, corrosion and wear resistance (Pillai et al. 2012). Although etched $\mathrm{NiP}$ by the oxidizing acids produces high absorptivity coating across the entire solar spectrum for terrestrial and space-born optical applications (Saxena et al. 2006). This work presents development black Ni-P coating to be used in a TSI radiometer absorptive cavity.

\section{Experimental}

The Ni-P coatings were deposited on aluminum circular discs with an area of $7.07 \mathrm{~cm}^{2}$. The aluminum substrates were mechanically polished, degreased in an ultrasonic acetone bath and after in an alkaline solution cleaner. Before the electroless plating the substrates 

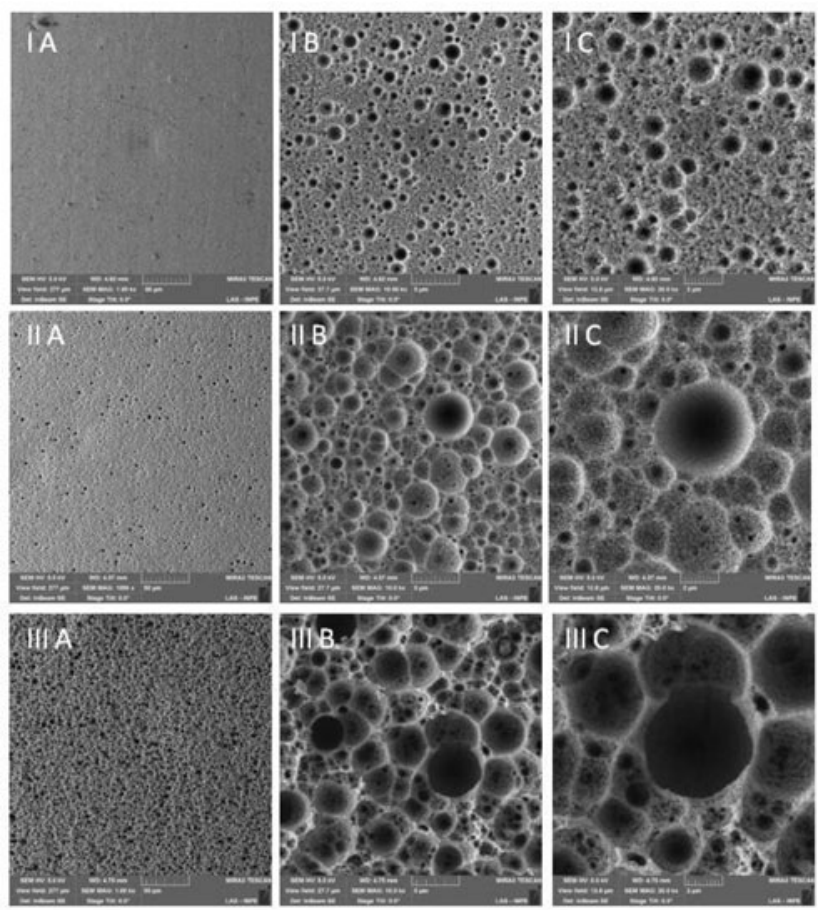

Figure 1. SEM image obtained in three magnification (A) $1 \mathrm{kX}$, (B) $2 \mathrm{kX}$ and (C) $3 \mathrm{kX}$ of black Ni-P coating with (I) $7.6 \% \mathrm{P}$, (II) $7.0 \% \mathrm{P}$ and (III) $5.9 \% \mathrm{P}$.

were deoxidized in acid cleaning solution and then a double zincate process aluminum was realized. Ni-P electroless bath was composed of Nickel sulfate, Sodium hypophosphite, Sodium citrate, Sodium acetate and Thiourea. Electroless conditions of the solution were were: ph $4.80-4.00$, bath temperature $363.15 \mathrm{~K}$, time deposition $180-420 \mathrm{~min}$ to get different thickness. After electroless deposition Ni-P layers were etched by oxidant acid $\left(\mathrm{HNO}_{3}\right)$ for $30-60 \mathrm{~s}$ at $313.15 \mathrm{~K}$ to produce Black Ni-P. Coatings morphology were observed by Field Emission Gun - Scanning Electron Microscopy (FEG-SEM, Tescan Mira 3 FEG) using accelerating voltage of $5 \mathrm{kV}$. The chemical microanalysis were realized with an energy dispersive spectroscopy (EDS) at an accelerating voltage of $15 \mathrm{kV}$ and working distance of $15 \mathrm{~mm}$. Spectral reflectance of black NIP were measured using a spectrophotometer (HITACHI U-3501) equipped with an integrating sphere, in $250 \mathrm{~nm}$ to $850 \mathrm{~nm}$ wavelength region. The solar absorptance were measured by solar reflectometer (410-Solar Reflectometer - Surface Optics Corporation). This instrument provide solarweighted absorptance and operate from $335 \mathrm{~nm}$ to $2500 \mathrm{~nm}$ wavelength region.

\section{Results and Discussion}

The composition of the Ni-P as deposited were around $5.9-7.5 \mathrm{Wt} \% \mathrm{P}$ and $25-50 \mu \mathrm{m}$ of thickness. The observed difference on the $\mathrm{P}$ percentage depends on the control of the bath operations conditions. Fig. 1 presents the morphological study of etched Ni-P. The blackned surface is characterized by high conical pore density with disordered distribution and different sizes. Black Ni-P coating with $5.9 \% \mathrm{P}$ and $50 \mu \mathrm{m}$ of thickness has larger and more pronounced crater which vary between $0.03-6 \mu \mathrm{m}$ of diameter and $2-7 \mu \mathrm{m}$ of depth. Black Ni-P exhibited lowest reflectance when greater pore quantity was formed 


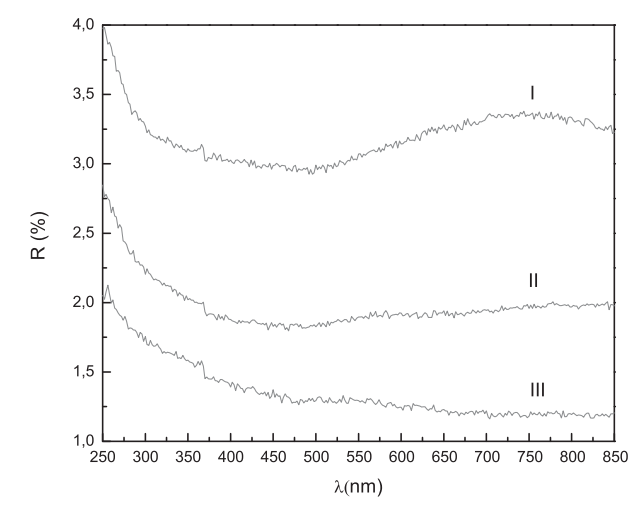

Figure 2. The total reflectance were measured as a function of wavelength of black Ni-P coating with different phosphorus content: (I) $7.6 \% \mathrm{P}$, (II) $7.0 \% \mathrm{P}$ and (III) $5.9 \% \mathrm{P}$.

during blackening process. The lower pre-etch $\mathrm{P}$ content studied in this work and relation with lower reflectance are accordingly with results obtained by Brown et al. (2002).

The spectral reflectance of electroless black coatings is shown in Fig. 2. Total reflectance change from 1.79 to $3.98 \%$ for pre-etch coatings with higher phosphorous content while the coating with $5.9 \% \mathrm{P}$ is between 1.16 and $2.21 \%$ in the range of $250-850 \mathrm{~nm}$. The solar-weighted absorptance measured by solar reflectometer is obtained integrating the spectral reflectance over the standard spectral irradiance distribution. Solar absorption $\left(\alpha_{S O L}\right)$ measured for sample III is $0.997 \pm 0.004$. The low reflectance is due conical pores that work as light trap resulting in better values of absorption.

\section{Summary}

The low reflectance of the black coating is associated with surface morphology obtained during blackening process and the chemical composition has influence in the size and depth of the pores. These results suggest that Black Ni-P can be used in high absorptivity cavities for a future Brazilian TSI radiometer project.

\section{References}

Steinhilber, F., Beer, J., \& Fröhlich, C. 2009, Geophys. Res. Lett., 36, 19

Haigh, J. D. 2007, Living Rev. Solar Phys, 4, 1

Kopp. G 2014, J. Space Weather Space Clim., 4, A14

Pillai,A. M.; Rajendra, A. \& Sharma, A. K. 2012, J Coat Technol Res, 9, 6

Saxena, V.; Uma Rani, R., \& Sharma, A. K. 2006, Surf. Coat. Technol., 201, 3-4

Brown, R. J. C.; Brewer, P. J., \& Milton, M. J. T. 2002, J. Mater. Chem., 12, 9 